\title{
Structural remedies in merger regulation in a Cournot framework
}

\author{
Andrei Medvedev
}

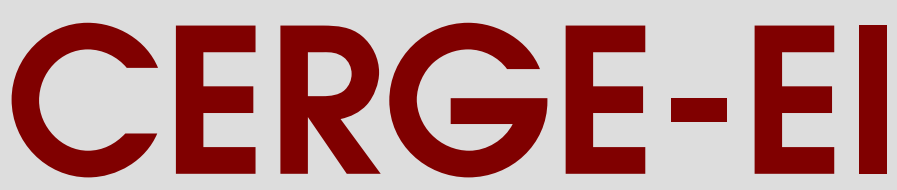

Charles University Center for Economic Research and Graduate Education Academy of Sciences of the Czech Republic Economics Institute 


\title{
Structural remedies in merger regulation in a Cournot framework*
}

\author{
Andrei Medvedev \\ CERGE, Prague ${ }^{\dagger}$
}

July 2004

\begin{abstract}
To prevent possible abuse of market power in the future an antitrust agency can force merging firms to divest some of their assets. The divested assets can be sold via auction either to existing competitors or to a new entrant. Divesture of assets extends the range of parameters when a merger satisfies a consumer surplus standard and should be approved. If the agency takes a more active stance toward the selection of a purchaser of the assets, then it could lead to a favorable outcome for consumers and merging firms.

Antitrustové agentury mohou donutit slucující se firmy zbavit se urcitých aktiv aby zabránily možnému zneužití dominantního postavení. Aktiva mohou být prodána formou aukce bud existujícím souperum na trhu, nebo firme na trh nove vstupující. Prodej aktiv rozširuje soubor parametru kdy fúze splnuje standard spotrebitelskho prebytku a má být povoleno. Aktivním postojem k volbe kupujícího prodávaných aktiv muže agentura dosáhnout lepších výsledku jak pro spotrebitele, tak pro fúzující firmy.
\end{abstract}

Keywords: merger regulation, structural remedies, efficiency, auction JEL classification: D43, K21, L51

*I am thankful to Eric van Damme, Avner Shaked, Jan Boone, Dirk Engelmann, Valter Sorana, Randall Filer, Valeri Nikolaev, and Dmitry Ryvkin for valuable discussions and suggestions.

${ }^{\dagger}$ Center for Economic Research and Graduate Education: andrei.medvedev@cerge-ei.cz 


\section{Introduction}

There is an extensive literature on mergers for different market structures and types of competition, which shows that if there are no cost reductions due to a merger, firms find it profitable to exercise their market power through a price increase, which decreases consumer surplus ${ }^{1}$.

An antitrust agency can choose between behavioral and structural remedies to restore effective competition in relevant markets ${ }^{2}$. Behavioral remedies set constraints on the merged firms' future behavior such as engagements by the merging parties not to abuse certain assets, to force compulsory licensing or to force access to intellectual property. However, in the case of behavioral remedies the prime difficulty is in overseeing the implementation of the remedies at the post-merger phase. In contrast, structural remedies modify the allocation of property rights and create new firms through entire or partial divesture of assets. In the EU the competition agency prefers to use structural remedies, because they are easy to implement and once implemented there is no need to monitor the behavior of merging firms afterwards ${ }^{3}$.

In this paper I analyze structural remedies in merger regulation. Although there are discussions by antitrust practitioners, academics, and lawyers, to the best of my knowledge the idea of structural remedies as a way to protect consumers is not formally analyzed in the literature. The model presented in this paper captures and allows a theoretical analysis of all main issues that are at stake when the agency makes a merger approval decision.

This paper extends the models by Shapiro and Farrell (1990), Perry and Porter (1985), McAfee and Williams (1992). These papers conduct an equilibrium analysis of a Cournot market before and after a merger with a focus on profitability and welfare changes. A common feature in those models is

\footnotetext{
${ }^{1}$ Salant et al. (1983), Perry and Porter (1985), Deneckere and Davidson (1985), Kamien and Zang (1990), Shapiro and Farrell (1990), Horn and Persson (2001).

"The vast majority of cases raising competition concerns were solved through viable remedies offered by the notifying parties in due time." Monti M., the EU Competition Commissioner, Paris, January 2002.

${ }^{3}$ See Monti (2002), Motta et al. (2002), Motta (2004).
} 
the existence of fixed capital (assets) in an industry. The amount of fixed capital in a firm's possession determines its production costs. In this paper I modify their analyses by allowing partial divesture of assets.

In order to prevent possible abuse of market power in the future the agency can force merging firms to divest some of their assets ${ }^{4}$. The divested assets can be sold either to existing competitors or to attract a new entrant into the market. One viable mechanism to sell divested assets is an auction. In this paper we analyze certain auction outcomes and possible ways to enhance consumer and total welfare. According to EU merger regulations ${ }^{5}$ merging firms suggest a purchaser, which must be approved by the agency. Therefore, the agency has veto power over the choice of a purchaser of divested assets.

If synergies (efficiencies) between merging firms are substantial, then prices might decrease after a merger, because cost reductions outweigh the market power effect ${ }^{6}$. This issue plays an important role in merger regulation since both the EU and US agencies allow for an efficiency defense in merger approvals ${ }^{7}$.

From the theoretical point of view the total welfare standard seems to be a relevant concept to apply in economic analysis. However, both EU and US antitrust agencies as well as academics now agree that the consumer welfare standard is the relevant standard to apply when making merger approval decisions. As it is stated in the EU and US, the prime objective of the antitrust agency is to protect consumers from price increases after a merger due to increased market power. For theoretical discussions about consumer vs. total surplus approaches in merger regulation see Motta (2004), Neven and Roller

\footnotetext{
${ }^{4}$ We can think about landing slots at airports that airlines possess, licences, radio or mobile phone frequencies, electricity generation facilities, etc. The agency can ask to divest a certain number of them as a structural remedy.

${ }^{5}$ The EU Merger Regulation and Competition Commission "Best practice guidelines for divesture commitments" published on http://europa.eu.int/comm/competition/mergers/legislation.

${ }^{6}$ See Williamson (1968), Werden (1996), Shapiro and Farrell (1990), Roller et al. (2000), Besanko and Spulder (1993).

${ }^{7}$ Medvedev (2004) discusses the effects of the inclusion of efficiency defense in merger regulation.
} 
(2000), Besanko and Spulder (1993). Policy relevance of the consumer surplus standard is discussed by Shapiro and Farrell (2001), Roller et al. (2000) and Yao and Dahdouh (1993). It is important to clarify that the agency is to protect consumers from price increases with minimum possible intervention rather than minimization of prices and protection of competitors. Therefore, in the present paper I assume that an antitrust agency applies a consumer surplus standard and wants to approve mergers that decrease prices, while rejecting those that increase prices.

The structure of the paper is as follows. In Section 2 I describe the basic model. Then I analyze a symmetric cost structure case, and proceed with a non-symmetric case. Then results are discussed, followed by a conclusion.

\section{Model}

Let us consider a market inverse demand function $P=a-b X$, where the total output $X=\sum_{i=1}^{n} x_{i}$ and $x_{i}$ is firm $i$ 's output. Each firm maximizes its profit: $\max _{x_{i}}(a-b X) x_{i}-C\left(x_{i}, s_{i}\right)$, where $s_{i}$ is firm's $i$ assets. The idea of the fixed capital $s$ in the industry is captured through a form of the cost function, $C\left(x_{i}, s_{i}\right)=\frac{d_{i}}{s_{i}} x_{i}$, such that the more capital a firm possesses, the lower the marginal costs of production. The parameter $d_{i}$ describes firm's $i$ production technology. Therefore, the market is characterized by constant marginal costs of production $C_{x_{i}}=\frac{d_{i}}{s_{i}}$. This is a simplified form of Perry and Porter's (1985), McAfee and Williams' (1992) cost function $C(x, s)=s g+d x+\frac{e}{2 s} x^{2}$ with marginal costs $C_{x}=d+\frac{e}{s} x$ and Shapiro and Farrell's (1990) cost function $C(x, s)=w x^{\frac{1}{b}} s^{-\frac{a}{b}}$ with marginal costs $C_{x}=\frac{w}{b} x^{\frac{1}{b}-1} s^{-\frac{a}{b}}$, where $s$ is the amount of fixed capital, and $a, b, e, d, g, w$ are constants. The constant marginal cost function allows us to capture the main feature of their functions, the inverse relation between assets and marginal costs, while simplifying derivations significantly. However, many results in the paper would be valid for any convex cost function with respect to a fixed capital $\left(C_{s}<0, C_{s s}>0\right)$. 
The equilibrium for a Cournot type of competition with constant marginal costs is the following. Each firm maximizes its profit:

$\max _{x_{i}}(a-b X) x_{i}-\frac{d_{i}}{s_{i}} x_{i}$ for $i=1, \ldots, n$. This implies a restriction on parameters: $a-\frac{d_{i}}{s_{i}}>0$. A firm with too little capital, such that $a-\frac{d_{i}}{s_{i}}<0$, would always prefer not to produce. Given demand and cost functions, the equilibrium output and price before the merger are derived from the system of $n$ first-order conditions (FOCs):

$$
a-2 b x_{i}-b \sum_{j=1, j \neq i}^{n} x_{j}=\frac{d_{i}}{s_{i}} .
$$

This yields $x_{i}=\frac{1}{(n+1) b}\left(a-n \frac{d_{i}}{s_{i}}+\sum_{j \neq i}^{n} \frac{d_{j}}{s_{j}}\right)$ as the output of the $i$-th firm ${ }^{8}$ and therefore the total market output is $X_{\text {total }}=\frac{1}{(n+1) b}\left(n a-\sum_{i=1}^{n} \frac{d_{i}}{s_{i}}\right)$.

Hence, the equilibrium price is $P=\frac{1}{n+1}\left(a+\sum_{i=1}^{n} \frac{d_{i}}{s_{i}}\right)$.

The profit of the $i$-th firm is $\Pi_{i}=\frac{1}{(n+1)^{2} b}\left[a-n \frac{d_{i}}{s_{i}}+\sum_{j=1, j \neq i}^{n} \frac{d_{j}}{s_{j}}\right]^{2}$.

\section{Symmetric case}

First, we derive a pre-merger equilibrium and then compare it with postmerger cases when there is no agency intervention and when the agency can force divesture, with the divested assets going either to an existing competitor or to a new entrant. The objective of the agency is to protect consumers from a price increase due to the merger. On the one hand the agency has veto power over a purchaser of the divested assets; on the other hand the agency approves a merger only if the price after the merger will not increase.

Consider first a symmetric case with $n=3$, i.e. each firm possesses an equal amount of fixed capital $s$ with $s_{1}=s_{2}=s_{3}=s$, and the same production technology, i.e. $d_{1}=d_{2}=d_{3}=d$, to get a feeling for how the system behaves.

\footnotetext{
${ }^{8}$ Further restrictions on exogenous parameters are: $x_{i}=\frac{1}{(n+1) b}\left(a-n \frac{d_{i}}{s_{i}}+\sum_{j \neq i}^{n} \frac{d_{j}}{s_{j}}\right) \geq 0$.
} 


\subsection{Pre-merger case}

The pre-merger equilibrium output of each firm is $x_{1}=x_{2}=x_{3}=\frac{1}{4 b}\left(a-\frac{d}{s}\right)$, the total output $X_{\text {total }}^{\text {Before }}=\frac{3}{4 b}\left(a-\frac{d}{s}\right)$,

the equilibrium price before the merger is $P^{\text {Before }}=\frac{1}{4}\left(a+3 \frac{d}{s}\right)$, the equilibrium profit of each firm is $\Pi_{i}^{\text {Before }}=\frac{1}{16 b}\left(a-\frac{d}{s}\right)^{2}$.

\subsection{Merger to duopoly without agency intervention}

When any two firms in the market merge the number of firms decreases and the market becomes more concentrated. However, the merged firm becomes twice the size of its competitor and possesses $(2 s)$ assets, which decreases its marginal costs of production. The equilibrium output and price after the merger is derived from the system of two FOCs for the merged firm (M) and the firm-outsider $(\mathrm{O})$ :

$\left\{\begin{array}{l}a-2 b x_{M}-b x_{o}=\frac{d}{2 s} \\ a-2 b x_{o}-b x_{M}=\frac{d}{s}\end{array} \Leftrightarrow\left\{\begin{array}{l}x_{M}=\frac{a}{3 b} \\ x_{o}=\frac{1}{3 b}\left(a-\frac{3 d}{2 s}\right)\end{array}\right.\right.$.

Therefore, the -total output is $X_{\text {total }}^{A f t e r}=\frac{1}{3 b}\left(2 a-\frac{3}{2} \frac{d}{s}\right)$.

Consequently, the equilibrium price is $P^{A}=a-b \frac{1}{3 b}\left(2 a-\frac{3}{2} \frac{d}{s}\right)=\frac{a}{3}+\frac{d}{2 s}$.

Corollary 1: The price after the merger will not increase, $P^{A} \leq P^{B}$, if $\frac{a}{3} \leq \frac{d}{s}$

Proof: Compare : $P^{A}=\frac{a}{3}+\frac{d}{2 s} \leq \frac{1}{4}\left(a+3 \frac{d}{s}\right)=P^{B} \quad \Leftrightarrow \quad \frac{a}{3} \leq \frac{d}{s}$.

The marginal costs of production of the merged firm could decrease substantially because the firm possesses more fixed capital. Lower marginal costs for the merged firm could outweigh the market power effect and be sufficient not to increase market price. This result copies Shapiro and Farrell (1990) ${ }^{9}$.

The profit of the merged firm is $\Pi_{M}=\frac{1}{9 b}\left[a-2 \frac{d}{2 s}+\frac{d}{s}\right]^{2}=\frac{a^{2}}{9 b}$.

\footnotetext{
${ }^{9}$ Shapiro and Farrell (1990) showed that a merger raises prices if and only if a markup of the would-be merging firms is less than the sum of the pre-merger markups at its constituent firms, where a merged firm produces just as much as its constituent firms together did before the merger.
} 
The profit of the outsider firm is $\Pi_{o}=\frac{1}{9 b}\left[a-2 \frac{d}{s}+\frac{d}{2 s}\right]^{2}=\frac{1}{9 b}\left[a-\frac{3}{2} \frac{d}{s}\right]^{2}$.

The merger is possible only if it is profitable for the merging firms themselves, i.e. if the joint profit after the merger is higher than the sum of profits before the merger when they are separate firms. However, this condition usually holds for a wide range of parameters ${ }^{10}$.

\subsection{Merger to duopoly with divesture to an existing competitor}

The agency can use structural remedies to "correct" the new market situation and keep prices at least unchanged after the merger. The agency can demand the merged firm to divest some of the obtained assets. The volume of divested assets is denoted by $\Delta$ with $\Delta \in\left[0, s_{j}\right]$, where $s_{j}$ is the amount of fixed assets that belongs to the acquired firm ${ }^{11}$. There is an upper limit on the amount the agency can ask the merged firm to divest because otherwise the merger makes no sense: by asking more, the agency would leave the acquiring firm with fewer assets than before the merger. If two firms merge they control $(2 s)$ assets. After the agency asks them to divest $(\Delta)$ assets $(2 s-\Delta)$ assets remain in their possession. If the divested assets go to an existing competitor, then the outsider to the merger possesses $(s+\Delta)$ assets. Equilibrium output and price are derived from the system of two FOCs for the merged firm (M) and the firm-outsider $(\mathrm{O})$ :

$\left\{\begin{array}{l}a-2 b x_{M}-b x_{o}=\frac{d}{2 s-\Delta} \\ a-2 b x_{o}-b x_{M}=\frac{d}{s+\Delta}\end{array} \Leftrightarrow\left\{\begin{array}{l}x_{M}=\frac{1}{3 b}\left[a-\frac{2 d}{2 s-\Delta}+\frac{d}{s+\Delta}\right] \\ x_{o}=\frac{1}{3 b}\left[a+\frac{d}{2 s-\Delta}-\frac{2 d}{s+\Delta}\right]\end{array}\right.\right.$.

Therefore, total output is $X_{\text {total }}^{A 1}(\Delta)=\frac{1}{3 b}\left[2 a-\frac{d}{(2 s-\Delta)}-\frac{d}{(s+\Delta)}\right]$.

$10 \Pi_{M}^{A}>\Pi_{1}^{B}+\Pi_{2}^{B} \Leftrightarrow \frac{a^{2}}{9 b}>2 \frac{1}{16 b}\left(a-\frac{d}{s}\right)^{2} \Leftrightarrow \frac{a}{3}(3-\sqrt{8})<\frac{d}{s}$. Given $\frac{a}{3}(3-\sqrt{8})<\frac{a}{3}$, it is always profitable for the merging firms to merge, if the price will not increase (Corollary 1: $\left.\frac{a}{3} \leq \frac{d}{s}\right)$.

${ }^{11}$ This is a general representation of merging firms' assets (a firm with more assets is acquiring and with fewer assets is acquired) although in this section we consider only the symmetric case in which all firms possess the same amount of assets $s$. In Section 4 we will look at non-symmetric case when firms have different amount of assets. 
Consequently, the equilibrium price is $P^{A 1}(\Delta)=\frac{1}{3}\left[a+\frac{d}{(2 s-\Delta)}+\frac{d}{(s+\Delta)}\right]$.

The profit of the merged firm is $\Pi_{M}^{A 1}=\frac{1}{9 b}\left[a-2 \frac{d}{2 s-\Delta}+\frac{d}{s+\Delta}\right]^{2}$ and the profit of the outsider is $\Pi_{o}^{A 1}=\frac{1}{9 b}\left[a-2 \frac{d}{s+\Delta}+\frac{d}{2 s-\Delta}\right]^{2}$. The merging firms will proceed with the merger only if it is profitable for them: $\Pi_{M}^{A 1}>\Pi_{1}^{B}+$ $\Pi_{2}^{B}$. However, like in the previous section, it is possible to show that this profitability constraint is not binding for parameters in which the price does not increase after the merger.

If we compare this situation with divesture to the one without (i.e. when the agency doesn't intervene), then the following proposition holds.

Proposition 1: Given a pre-merger symmetric cost structure $\left(s_{1}=s_{2}=s_{3}\right.$ and $\left.d_{1}=d_{2}=d_{3}\right)$, any divesture $\Delta \in(0 ; s)$ leads to lower prices than would prevail without divesture.

Proof: $P^{A 1}$ will never exceed $P^{A}: \frac{1}{3}\left[a+\frac{d}{(2 s-\Delta)}+\frac{d}{(s+\Delta)}\right] \leq \frac{a}{3}+\frac{d}{2 s} \Leftrightarrow$ $\frac{1}{2 s-\Delta}+\frac{1}{s+\Delta} \leq \frac{3}{2 s} \quad \Leftrightarrow \quad 2 s^{2} \leq(2 s-\Delta)(s+\Delta) \quad \Leftrightarrow \quad 0 \leq \Delta(s-\Delta)$.

The divesture, therefore, leads to a more symmetric market ${ }^{12}$. From the proposition above it is seen that no matter how large the decrease in marginal costs due to more fixed capital for the merged firm, it is always better to divest some assets and restore the symmetry: take assets from the bigger firm and give it to the smaller one. This results from the convexity of the cost function, $\left(C_{x}=\frac{d}{s}\right)$ : marginal costs are inversely related to the amount of fixed capital a firm possesses. Given firms' identical cost structures and Cournottype competition the maximum output and the lowest price are achieved when all firms in the market possess an equal amount of fixed capital ${ }^{13}$, i.e. in case of duopoly the best result is achieved when $\left(\frac{s}{2}\right)$ assets are divested and both firms possess $\left(\frac{3}{2} s\right)$.

Therefore, we can distinguish three effects that affect equilibrium price in

\footnotetext{
${ }^{12}$ One of the measurements of symmetry of the market is the Herfindahl-Hirschman index: the higher the HHI, the less symmetric a market.

${ }^{13}$ From the empirical studies we know that a more symmetric market could lead to collusion between firms and, consequently, higher prices. In this paper, the cost function convexity effect outweighs the collusive effect and more equal distribution of assets leads to lower prices.
} 
the market: number of players, marginal costs, and symmetry of the market. The number of players in the market and the degree of symmetry negatively affect the price, while marginal costs positively affect the price.

As discussed above the prime objective of EU and US antitrust agencies is to protect consumers from price increases after the merger due to increased market power and, because the agency doesn't pay attention to firms' profits (or absence of it), the agency chooses that divesture which keeps price unchanged rather than the one that minimizes price. From Section 3.2 we know that if $\frac{a}{3} \leq \frac{d}{s}$ we do not need any divesture to ensure that prices do not increase, i.e. $\Delta=0$. Now consider the case $\frac{a}{3}>\frac{d}{s}$ and how many assets the agency should demand the merging firms to divest in order to keep prices at the pre-merger level, i.e. $P^{A 1} \leq P^{B}$ :

$\frac{1}{3}\left[a+\frac{d}{(2 s-\Delta)}+\frac{d}{(s+\Delta)}\right] \leq \frac{1}{4}\left(a+3 \frac{d}{s}\right) \quad \Leftrightarrow$

$-\Delta^{2}+s \Delta+2 s^{2} \frac{3 d-a s}{9 d-a s} \geq 0$.

The solutions to this quadratic expression are the following:

$\Delta^{\text {Required }}=\frac{-s \pm s \sqrt{1+8 \frac{3 d-a s}{9 d-a s}}}{-2}=\frac{-s \pm s \sqrt{\frac{33 d-9 a s}{9 d-a s}}}{-2}$.

The expression under the square root should be positive but less than one, $0 \leq \frac{33 d-9 a s}{9 d-a s} \leq 1$, to ensure that the divesture is less than $s$ assets (otherwise the agency asks to divest more than the acquiring firm obtained from the merger). Clearly, $(33 d-9 a s)<(9 d-a s)$, so if $(9 d-a s)<0$, then $|33 d-9 a s|$ $>|9 d-a s|$ and the square root expression is more than 1 . Hence, given $(9 d-a s)>0$, the price will stay unchanged after the merger if:

$\Delta_{1}^{R e q}=\frac{-s+s \sqrt{\frac{33 d-9 a s}{9 d-a s}}}{-2} \leq \frac{s}{2}$ or $\Delta_{2}^{R e q}=\frac{-s-s \sqrt{\frac{33 d-9 a s}{9 d-a s}}}{-2} \geq \frac{s}{2}$,

and the following inequalities hold: $0 \leq \frac{33 d-9 a s}{9 d-a s} \leq 1 \quad \Leftrightarrow \quad \frac{9 a}{33} \leq \frac{d}{s} \leq \frac{a}{3}$.

There are two solutions to the quadratic equation, but the one with least divesture, $\Delta_{1}^{R e q}$, should be the focus of the analysis. Both solutions lead to the same result (keeping the price unchanged) and the agency should choose the one with minimum possible intervention into the market because 
otherwise $\Delta_{2}$ would make the outsider to the merger the largest firm.

The results show that the possibility of divesture of assets from the merging firms extends the range of parameters that satisfy a consumer surplus standard from $\frac{a}{3} \leq \frac{d}{s}$ (case of a merger without divesture) to $\frac{9 a}{33} \leq \frac{d}{s}$. On the interval $\frac{9 a}{33} \leq \frac{d}{s} \leq \frac{a}{3}$ there is a divesture $\Delta$ between 0 and $\frac{s}{2}$ that would keep the price after the merger unchanged. If $\frac{9}{33} a=\frac{d}{s}$, then $\Delta^{R e q}=\frac{s}{2}$, i.e. the merged firm should divest exactly half of what it obtained through the merger and, therefore, two firms in the market would possess an equal amount of fixed capital (as we noted above, this is the divesture that maximizes consumer surplus $)^{14}$.

\subsubsection{Efficiencies}

There could be efficiency gains due to merger-specific synergies between merging firms' assets. In our setting this is equivalent to a decrease in the parameter $d$ (from $d$ to $\alpha d$, where $\alpha \in[0,1]$ ) for the merged firm. If divested assets $(\Delta)$ go to a competitor, then the merged firm possesses $(2 s-\Delta)$, while the competitor has $(s+\Delta)$ assets. At the same time it is assumed that the merging firms are able to achieve efficiencies even if some of their combined assets are divested. Equilibrium output and price are derived from the system of two FOCs for the merged firm (M) and the outsider (o):

$\left\{\begin{array}{l}a-2 b x_{M}-b x_{o}=\frac{\alpha d}{2 s-\Delta} \\ a-2 b x_{o}-b x_{M}=\frac{d}{s+\Delta}\end{array} \Leftrightarrow\left\{\begin{array}{l}x_{M}=\frac{1}{3 b}\left[a-\frac{2 \alpha d}{2 s-\Delta}+\frac{d}{s+\Delta}\right] \\ x_{o}=\frac{1}{3 b}\left[a+\frac{\alpha d}{2 s-\Delta}-\frac{2 d}{s+\Delta}\right]\end{array}\right.\right.$.

Therefore, total output is $X_{\text {total }}^{A 1}(\alpha)=\frac{1}{3 b}\left[2 a-\frac{\alpha d}{(2 s-\Delta)}-\frac{d}{(s+\Delta)}\right]$.

Consequently, the equilibrium price will be $P^{A 1}(\alpha)=\frac{1}{3}\left[a+\frac{\alpha d}{(2 s-\Delta)}+\frac{d}{(s+\Delta)}\right]$.

Proposition 2: The price after the merger will not increase, $P^{A 1}(\alpha) \leq P^{B}$, if $\alpha \leq(2 s-\Delta)\left[\frac{1}{4}\left(\frac{9}{s}-\frac{a}{d}\right)-\frac{1}{s+\Delta}\right]$.

Function $\Delta(\alpha)$ could be plotted for given values of parameters $a$ and $d$ (see

\footnotetext{
${ }^{14}$ Given required divesture the merger must be profitable for the merging firms as we discussed before.
} 
Figure 1). The line captures a trade-off between efficiency gains due to the merger and divested assets the agency asks the merged firm to sell-off to the competitor in order to keep prices unchanged after the merger ${ }^{15}$. This trade-off plays an important role in merger regulation after both the EU and US agencies recently allowed for efficiency defense in merger approvals. It illustrates that the amount of divested assets depends on verified efficiencies merging firms are able to bring in front of the agency.

The inclusion of an exogenously given "synergy parameter" $\alpha$ implies that the cost function is not continuous in $s$ anymore and it leads to a shift in marginal cost function, i.e. our convexity assumption is violated. The problem with such types of changes in parameters is that they are exogenously given.

\subsection{Merger with divesture to a new entrant}

The agency could also enforce divesture of $(\Delta)$ assets to a new entrant into the market. Therefore, the merging firms possess $(2 s-\Delta)$ assets, old competitor has $(s)$ assets, while their new competitor has $(\Delta)$ assets. Equilibrium output and price are derived from the system of three FOCs for the merging firms $(\mathrm{M})$, a firm-outsider $(\mathrm{o})$, and a new entrant to the market $(\mathrm{N})$ :

$\left\{\begin{array}{l}a-2 b x_{M}-b x_{o}-b x_{N}=\frac{d}{2 s-\Delta} \\ a-2 b x_{o}-b x_{M}-b x_{N}=\frac{d}{s} \\ a-2 b x_{N}-b x_{M}-b x_{o}=\frac{d}{\Delta}\end{array} \Leftrightarrow\left\{\begin{array}{l}x_{M}=\frac{1}{4 b}\left[a-\frac{3 d}{2 s-\Delta}+\frac{d}{s}+\frac{d}{\Delta}\right] \\ x_{o}=\frac{1}{4 b}\left[a+\frac{d}{2 s-\Delta}-\frac{3 d}{s}+\frac{d}{\Delta}\right] \\ x_{N}=\frac{1}{4 b}\left[a+\frac{d}{2 s-\Delta}+\frac{d}{s}-\frac{3 d}{\Delta}\right]\end{array}\right.\right.$.

Therefore, total output is $X_{\text {total }}^{A 2}=\frac{1}{4 b}\left[3 a-\frac{d}{2 s-\Delta}-\frac{d}{s}-\frac{d}{\Delta}\right]$.

Consequently, the equilibrium price is $P^{A 2}=\frac{1}{4}\left[a+\frac{d}{2 s-\Delta}+\frac{d}{s}+\frac{d}{\Delta}\right]$.

Proposition 3: If the pre-merger market is characterized by a symmetric cost structure $\left(s_{1}=s_{2}=s_{3}\right.$ and $\left.d_{1}=d_{2}=d_{3}=d\right)$ and a new entrant

\footnotetext{
${ }^{15}$ As we discussed above in a Cournot-type competition the maximum output and the lowest price are achieved when market structure is symmetric, i.e. firms have equal marginal costs. In the presence of efficiencies $\alpha$ it means that this best outcome is achieved when $\frac{\alpha d}{2 s-\Delta}=\frac{d}{s+\Delta} \Leftrightarrow \Delta=s \frac{2-\alpha}{1+\alpha}$.
} 
possesses the same technology as all other firms $\left(d_{N}=d\right)$, then there is no such divesture $\Delta$ to a new entrant that would decrease prices after the merger.

Proof: Prices after the merger with a divesture to a new entrant, $P^{A 2}$, is always greater than prices before the merger, $P^{B}$ :

$$
\begin{aligned}
& P^{A 2}=\frac{1}{4}\left[a+\frac{d}{(2 s-\Delta)}+\frac{d}{s}+\frac{d}{\Delta}\right] \geq \frac{1}{4}\left[a+3 \frac{d}{s}\right]=P^{B} \\
& \Leftrightarrow \quad \frac{1}{(2 s-\Delta)}+\frac{1}{\Delta} \geq \frac{2}{s} \Leftrightarrow s^{2} \geq(2 s-\Delta) \Delta \Leftrightarrow(s-\Delta)^{2} \geq 0 .
\end{aligned}
$$

The price will never decrease due to the form of the marginal cost function $\left(\frac{d}{s}\right)$. Under the symmetric cost structure and a Cournot type of competition the maximum output and lowest price are achieved when all firms possess an equal amount of fixed capital (which is the case for the pre-merger situation). After the merger the number of players stays the same (one firm is eliminated through the merger but a new one is formed) but the cost structure becomes less symmetric ${ }^{16}$.

Remark 1: It is possible to show that this proposition is valid for any convex cost function with respect to fixed capital $\left(C_{s}<0, C_{s s}>0\right)$.

From Sections 3.3 and 3.4 it is seen that if the pre-merger market is characterized by a symmetric cost structure, then the agency would never approve a merger with a divesture of assets to a new entrant. Therefore, there is no need to auction the divested assets because an existing competitor is the only potential purchaser of the assets that could be approved by the agency. However, if a market is characterized by a non-symmetric cost structure an auction can lead to different outcomes.

\section{Non-symmetric case}

First consider a three-firm industry with identical technology parameters for the marginal cost function $d=d_{1}=d_{2}=d_{3}$ but unequal amounts of fixed

\footnotetext{
${ }^{16}$ There is an increase in market concentration. The market becomes less symmetric and the Herfindahl index goes up: the merged firm is bigger than firm 1 before the merger $(2 s-\Delta>s)$ and a new entrant is smaller than firm $2(\Delta<s)$.
} 
capital $s_{1}, s_{2}, s_{3}$.

Proposition 4: If firms in the market differ only in the amount of fixed capital they possess then a merger between any two firms with divesture to a new entrant leads to a price increase.

Proof: This proposition follows from the convexity of the cost function. Assume the price after the merger is lower than before the merger:

$P^{\text {Before }}=\frac{1}{4}\left[a+\frac{d}{s_{1}}+\frac{d}{s_{2}}+\frac{d}{s_{3}}\right]>\frac{1}{4}\left[a+\frac{d}{\left(s_{1}+s_{2}-\Delta\right)}+\frac{d}{s_{3}}+\frac{d}{\Delta}\right]=P^{\text {NonSym }}$

$\frac{d}{s_{1}}+\frac{d}{s_{2}}>\frac{d}{s_{1}+s_{2}-\Delta}+\frac{d}{\Delta} \Leftrightarrow \frac{1}{s_{1}}+\frac{1}{s_{2}}>\frac{1}{s_{1}+s_{2}-\Delta}+\frac{1}{\Delta} \Leftrightarrow s_{1} s_{2}<\left(s_{1}+s_{2}\right) \Delta-\Delta^{2}$. Inequality holds if $\Delta \in\left(s_{2}, s_{1}\right)$ assuming $s_{2}<s_{1}$, which requires to divest more than was acquired. This is impossible due to an initial assumption.

Remark 2: It is possible to show that this proposition is valid for any convex cost function with respect to fixed capital.

Conclusion: Like the symmetric case the agency will never approve divesture of assets to a new entrant. For certain values of parameters it can approve a sale of the divested assets to the existing competitor, or approve the merger without any divesture, or reject the merger. Therefore, this nonsymmetric case does not provide us with any new insights on the divesture problem.

Consider a three-firm industry with an equal amount of assets across firms $s_{1}=s_{2}=s_{3}=s$ but with different technology parameters $d_{1}, d_{2}, d_{3}$. Assume that firm 1 and 2 are merging and the merged firm would produce at marginal costs which are the lower of the two merging firms ${ }^{17}$. Without loss of generality we can assume that $d_{1}<d_{2}$.

Then there are again 2 cases:

a) A merger between two firms with divesture to the existing competitor. The equilibrium price in the non-symmetric case with the divesture to an existing competitor $\left(P^{E C}\right)$ is $P^{E C}=\frac{1}{3}\left[a+\frac{d_{1}}{2 s-\Delta}+\frac{d_{3}}{s+\Delta}\right]$.

\footnotetext{
${ }^{17}$ In the literature this is known as a rationalization of production, i.e. a shift of output to the facility with lower marginal cost (see Shapiro and Farrell 1990).
} 
b) A merger between two firms with divesture to a new entrant. The marginal costs of production for a new entrant are characterized by parameter $d_{N}$. This parameter determines viability of a new entrant, which is a prime concern for the EU Competition Commission when deciding on the divesture of $\operatorname{assets}^{18}$. The equilibrium price in the non-symmetric case with the divesture to a new entrant $\left(P^{N E}\right)$ is $P^{N E}=\frac{1}{4}\left[a+\frac{d_{1}}{2 s-\Delta}+\frac{d_{3}}{s}+\frac{d_{N}}{\Delta}\right]$.

In merger approval decisions the agency and the merging firms negotiate the required amount of divested assets $\Delta$ and then can decide to auction it. In principle an auction seems a viable mechanism to sell divested assets and often parties in interest opt for $i^{19}$. At the auction either an existing competitor or a new entrant purchases the divested assets. The winner of the auction determines the market structure and, consequently, prices. The agency approves a purchaser only if the price will not increase. At the same time a merger and, consequently, a divesture are possible only if the merger is beneficial for the merging firms themselves (firm 1 and 2 ), i.e. if the merging firms expect a higher joint profit after the merger than the sum of profits before the merger when they are separate firms: $\Pi_{1}^{\text {Before }}(s)+\Pi_{2}^{\text {Before }}(s)<\Pi_{\text {Merged }}^{\text {After }}(2 s-\Delta)$. It is worth noticing that divesture is a plausible instrument only if the exogenous parameters are such that without any agency intervention the price will increase after the merger (as in Remark 1, Section 3.2), i.e. only if $P^{\text {Before }}<P^{\text {After }}$ (without divesture). ${ }^{20}$

The analysis proceeds in the following way. First, given exogenous parameters and values of $\Delta$ between 0 and $s$ we check who has the higher expected profit from the purchase of the divested assets: an existing competitor or a new entrant. Then, given the amount of divested assets and the winner at the auction we check whether the merger is profitable for the merging firms. Finally, we answer what will happen to the price, since the agency approves the divesture only if it will not increase the price.

\footnotetext{
${ }^{18}$ Exogenous parameters should satisfy a condition: $x_{N}=\frac{1}{4 b}\left(a+\frac{1}{2 s-\Delta}+\frac{d_{3}}{s}-3 \frac{d_{N}}{\Delta}\right)>0$

${ }^{19} \mathrm{An}$ alternative to the auction is a direct sale of assets.

${ }^{20}$ Further in the paper we will consider only such values of exogenous parameters, i.e. $P^{\text {Before }}=\frac{1}{4}\left[a+\frac{d_{1}}{s}+\frac{d_{2}}{s}+\frac{d_{3}}{s}\right]<\frac{1}{3}\left[a+\frac{d_{1}}{2 s}+\frac{d_{3}}{s}\right]=P^{A f t e r}$ (without divesture).
} 
In Section 4.1-4.3 we formally introduce the conditions mentioned above and then (Section 4.4) proceed with the analysis of possible auction outcomes.

\subsection{Incentives for an existing competitor and a new entrant to purchase the divested assets}

The existing competitor (firm 3) compares profits when it purchases divested assets $(\Delta)$ and then operates in a duopoly market with the situation in which it stays away from the purchase while a new entrant buys the assets. The profit of the existing competitor if it purchases divested assets and operates in a duopoly market is $\Pi_{3}^{\text {buys }}=\frac{1}{3^{2} b}\left[a-2 \frac{d_{3}}{s+\Delta}+\frac{d_{1}}{2 s-\Delta}\right]^{2}$, while the profit of the existing competitor if it stays away from the purchase while a new entrant buys the assets is $\Pi_{3}^{\text {away }}=\frac{1}{4^{2} b}\left[a-3 \frac{d_{3}}{s}+\frac{d_{1}}{2 s-\Delta}+\frac{d_{N}}{\Delta}\right]^{2}$. If a new entrant purchases divested assets then its profit is $\Pi_{N}=\frac{1}{4^{2} b}\left[a-3 \frac{d_{N}}{\Delta}+\frac{d_{1}}{2 s-\Delta}+\frac{d_{3}}{s}\right]^{2}$. Therefore, if the inequality $\Pi_{3}^{\text {buys }}-\Pi_{3}^{\text {away }}>\Pi_{N}$ holds, then the existing competitor bids a higher price than a new entrant, because its increase in expected profit from buying the assets is higher. Here and later on in the paper without loss of generality we can assume that $s=1$ and $d_{1}=1$ to simplify the further calculations. With this the above condition becomes:

$\frac{16}{9}\left[a-2 \frac{d_{3}}{1+\Delta}+\frac{1}{2-\Delta}\right]^{2}-\left[a-3 d_{3}+\frac{1}{2-\Delta}+\frac{d_{N}}{\Delta}\right]^{2}>\left[a-3 \frac{d_{N}}{\Delta}+\frac{1}{2-\Delta}+d_{3}\right]^{2}$.

There are 4 exogenous parameters in the model $\left(a, d_{2}, d_{3}, d_{N}\right)$, hence it is difficult to explicitly derive conditions for the inequality to hold. However, given certain values of exogenous parameters, it is seen (Graph 1) that by changing values of $\Delta$ the divested assets could be purchased either by a new entrant or by the existing competitor.

\subsection{Incentives for the merging firms}

The merging firms (firm 1 and 2) proceed with the merger if the expected joint profit after the merger is higher than the sum of profits before the merger when they are separate firms: $\Pi_{1}^{\text {Before }}(s)+\Pi_{2}^{\text {Before }}(s)<\Pi_{\text {Merger }}^{\text {After }}(2 s-\Delta)$. Depending on who wins the auction the condition above becomes: 
a) if the existing competitor purchases the assets (given $s=1$ and $d_{1}=1$ )

$\frac{1}{16 b}\left[a-3+d_{2}+d_{3}\right]^{2}+\frac{1}{16 b}\left[a+1-3 d_{2}+d_{3}\right]^{2}<\frac{1}{9 b}\left[a-2 \frac{1}{2-\Delta}+\frac{d_{3}}{1+\Delta}\right]^{2}$

b) if a new entrant purchases the assets

$\frac{1}{16 b}\left[a-3+d_{2}+d_{3}\right]^{2}+\frac{1}{16 b}\left[a+1-3 d_{2}+d_{3}\right]^{2}<\frac{1}{16 b}\left[a-3 \frac{1}{2-\Delta}+d_{3}+\frac{d_{N}}{\Delta}\right]^{2}$.

\subsection{Price change after a divesture}

a) If the divested assets go to the existing competitor, then the price will not increase after the merger if

$P^{\text {Before }}=\frac{1}{4}\left[a+\frac{d_{1}}{s}+\frac{d_{2}}{s}+\frac{d_{3}}{s}\right] \geq \frac{1}{3}\left[a+\frac{d_{1}}{2 s-\Delta}+\frac{d_{3}}{s+\Delta}\right]=P^{E C}$.

Given the assumptions $s=1$ and $d_{1}=1$, we obtain the following inequality: $3\left(1+d_{2}+d_{3}\right) \geq a+4 \frac{1}{2-\Delta}+4 \frac{d_{3}}{1+\Delta}$.

b) If the divested assets go to a new entrant then the price will not increase after the merger if

$P^{\text {Before }}=\frac{1}{4}\left[a+\frac{d_{1}}{s}+\frac{d_{2}}{s}+\frac{d_{3}}{s}\right] \geq \frac{1}{4}\left[a+\frac{d_{1}}{2 s-\Delta}+\frac{d_{3}}{s}+\frac{d_{N}}{\Delta}\right]=P^{N E}$.

Given the assumptions $s=1$ and $d_{1}=1$, we obtain: $\quad 1+d_{2} \geq \frac{1}{2-\Delta}+\frac{d_{N}}{\Delta}$.

\subsection{Possible divesture auction outcomes}

In this section we investigate outcomes of the auction of divested assets and possible ways to enhance consumer welfare. It is difficult to solve analytically the full system of inequalities above because there are 6 exogenous parameters $a, d_{1}, d_{2}, d_{3}, d_{N}, s$. We know that $d_{1}<d_{2}$ and without loss of generality we can assume that $s=1$ and $d_{1}=1$, and conditions $a>\frac{d_{i}}{s_{i}}$ and $x_{i}=(a-$ $\left.n \frac{d_{i}}{s_{i}}+\sum_{j \neq i}^{n} \frac{d_{j}}{s_{j}}\right)>0$ must hold. This, however, is still analytically intractable. Hence, we conduct a numerical analysis and look at some possible outcomes of structural remedies.

The crucial parameters in the model are the firms' marginal costs. The table 
below reflects the technology parameters $d_{i}$ of each firm relative to all others. The columns contain a ranking of the two merging firms' parameters $\left(d_{1}\right.$ and $d_{2}$ ) relative to the outsider to the merger $\left(d_{3}\right)$. In the rows is a ranking of a new entrant's parameter $\left(d_{N}\right)$ relative to the three pre-merger firms ${ }^{21}$.

\begin{tabular}{c|ccc}
\hline & \multicolumn{3}{|c}{ Merging firms } \\
& \multicolumn{3}{|c}{$d_{1}$ and $d_{2}$ wrt $d_{3}$} \\
\hline New entrant $d_{N}$ & Two lowest & Two highest & Lowest and Highest \\
\hline Lowest & Case 1 & Case 2 & Case 3 \\
b/w first and second & Case 4 & Case 5 & Case 6 \\
b/w second and third & Case 7 & Case 8 & Case 9 \\
Highest & Case 10 & Case 11 & Case 12
\end{tabular}

A numerical analysis is conducted using MATLAB software (see a sample of the code in the Appendix). Without loss of generality it is assumed that $a=4$ ( $a$ is a parameter of the inverse demand function). We check for different types of equilibria for $\Delta \in(0 ; 1)$ (grid is 100) and parameters $d_{2}, d_{3}, d_{N} \in$ $(0 ; 4)$ (grid is 100). Given inequalities in Sections 4.1-4.3 and conditions in footnotes 8 and 20, the following results are obtained.

The viability of a new entrant that is captured by the ratio $\frac{d_{N}}{\Delta}$ is crucial for the firm's competitiveness. If $\Delta$ is small or $d_{N}$ is high then the condition $x_{N}=\frac{1}{4 b}\left(a+\frac{1}{2-\Delta}+d_{3}-3 \frac{d_{N}}{\Delta}\right)>0$ does not hold, i.e. a new entrant cannot have a positive output level. It is seen that the higher $d_{3}$, marginal costs of the existing competitor, and the more efficient a new entrant relative to the merging firms (which is normalized to one), the more likely the condition is to hold. If the condition does not hold, then the existing competitor would always win the auction whenever it is profitable for him and for the merging firms (see Section 4.2); otherwise the merger would not happen. Depending on the exogenous parameters the price will increase or decrease, and hence the merger will be rejected or approved by the agency, respectively.

There are parameters when a new entrant wins the auction, the price decreases, and it is profitable for the merging firms to proceed with the merger

\footnotetext{
${ }^{21}$ There are 4 parameters $\left(d_{1}, d_{2}, d_{3}, d_{N}\right)$ and $(4 !)=24$ combinations when the order matters. Assuming $d_{1}<d_{2}$ there are only 12 possible cases left.
} 
and divesture. From the numerical analysis we can say that such a situation can emerge in Cases 1, 2, 3 (it appears most frequently in Case 1, for example: $\left.a=4, d_{1}=1, d_{2}=1.33, d_{3}=1.77, d_{N}=0.44, \Delta=0.36\right)$. In all these cases a new entrant is the most efficient firm in the market $\left(d_{N}\right.$ is the lowest among all firms ${ }^{22}$. Although in many industries it is difficult to imagine that a firm which is a newcomer to a market could possess the most advanced technology there are cases where it could be true. For example, there is tough competition to operate flights from Heathrow Airport in London. Landing slots are the necessary assets to do business. Incumbents (British Airways, United, and others) do not allow other airlines to buy or lease landing slots at the airport so as to keep competitors away from the lucrative transatlantic flight business. However, it is possible that a low-cost carrier could enter the market ${ }^{23}$ by buying divested assets and turn out to be the most efficient player (efficient enough to reduce the price in the market). Probably a new efficient entrant needs not many assets to start a profitable business: if a new entrant is efficient, $d_{N}$ is small, then divesture $\Delta$ could be small. At the same time 'little' divesture keeps the merger profitable for the merging firms. In this case the results of the auction are beneficial for all parties involved: consumers, merging firms, and a new entrant.

Another situation is when a new entrant wins the auction and the price decreases, but this new market structure is unprofitable for the merging firms. This is possible in Cases 1, 2, 3, and 5 (it appears most frequently in Case 1, for example: $\left.a=4, d_{1}=1, d_{2}=1.2, d_{3}=1.3, d_{N}=0.5, \Delta=0.80\right)$. In this situation we can use the same example of Heathrow Airport as above with the only difference that the merging firms would not allow the divesture to a new entrant to happen. Appearance of a new more efficient competitor will

\footnotetext{
${ }^{22}$ An efficient new entrant could have entered the market before the merger by buying assets from "inefficient" incumbents and compensating them forgone profits. However, the entrance of a new firm into the market would increase the number of players from 3 to 4 and this in its turn negatively affects price and could make such a purchase unprofitable. The purchase of all assets of an incumbent by an efficient new entrant (so the number of firms in the market stays the same) represents a full takeover and is not considered in the merger regulation.

${ }^{23}$ Here the definition of the market is flights from Heathrow.
} 
decrease their future profits. Therefore the merging firms prefer to abandon the merger.

It is possible that if a new entrant wins the auction, the price would decrease and it would be profitable for the merging firms, but the existing competitor bids a higher price for the assets and a new market structure either leads to higher prices or makes the merger unprofitable for the merging firms ${ }^{24}$.

The situation which leads to higher prices can emerge in Cases 1, 2, 3, 5, and 8 (it appears most frequently in Case 2, for example: $a=4, d_{1}=1, d_{2}=$ $\left.1.2, d_{3}=0.9, d_{N}=0.8, \Delta=0.6\right)$, i.e. when either a new entrant is the most efficient firm or the merging firms are the least efficient firms in the premerger market (firms 1 and 2 have the highest marginal costs). The existing competitor does not allow the merger to happen simply by overbidding a new entrant and causing the price to increase. As a result the agency rejects the purchaser of divested assets and the merger, the merging firms have to abandon the merger and forgo expected profits in the future, and consumers have to stay with the pre-merger price, which could have decreased due to the merger.

The situation in which divesture to the existing competitor makes the merger unprofitable can emerge in Cases 1, 3, 4, 6, 8, 9 (it appears most frequently in Case 4, for example: $a=4, d_{1}=1, d_{2}=1.47, d_{3}=1.68, d_{N}=1.26, \Delta=$ 0.79). As a result the merging firms have to abandon the merger and forgo expected profits in the future, and consumers have to stay with the premerger price, which could have decreased due to the merger with divesture to a new entrant.

In both cases the agency (and consumers) would be better off if a new entrant wins the auction. Therefore, by excluding the existing competitor (incumbent) from the auction the agency can enhance consumer and merging firms'

\footnotetext{
${ }^{24}$ Here in the paper we do not consider auction revenue from the sale of divested assets. An inclusion of an auction revenue requires explicitly to assume and model the type of auction, but this is outside of the scope of this paper. An addition of the auction revenue would reduce but not eliminate the number of situations when a merger with divesture is unprofitable for the merging firms.
} 
welfare. Furthermore, this policy is easy to implement.

Whenever a new entrant has the highest marginal costs among all firms (Case $10,11,12)$ and the assets are divested to it, the price will always increase and the agency will reject the divesture and, consequently, the merger. The intuition is that given that the number of firms in the market stays the same (three), and with convexity of the marginal cost function it is unreasonable to divest assets from an 'efficient' to a less efficient new entrant because in the model the market price depends on the sum of marginal costs across all firms.

Under a wide range of parameters the existing competitor wins the auction, the price decreases, and such a market structure is profitable for the merging firms to proceed with the merger. However, the price could also increase in some cases or a new market structure could be unprofitable for the merging firms. These results are similar to those discussed in the symmetric case.

\section{Conclusion}

The model presented here introduces a simple theoretical framework to analyze structural remedies in merger regulation. It captures all the main issues that are at stake in merger approval decisions: efficiency defense and consumer welfare, amount of divesture and auction design, viability of a new entrant and rationalization of output between merging firms.

Under the current merger guidelines the merging firms can sell divested assets through an auction, while a purchaser of the assets must be approved by the agency. Evidently the merging firms choose a purchaser, which is the most profitable for them based on future profit from a new market structure. The agency only checks whether the price will decrease or increase after the purchase and, subsequently, will approve or reject a purchaser and the merger.

The analysis of the symmetric case shows that divesture allows for the ex- 
tension of the range of parameters when a merger should be approved. The non-symmetric case shows the importance of the rationalization of production between the merging firms and the viability of a new entrant.

From the results of the numerical analysis we can suggest making the agency more active in the selection of a potential purchaser of divested assets. The agency can stipulate in the merger guidelines that first they want to look for a new entrant (a viable one) and only if one is not found or not desirable, to consider existing competitors. For some parameters the agency is better off to exclude the existing competitor (incumbent) from the auction. As was shown in the paper, this could lead to a more favorable outcome for consumers and merging firms.

\section{References}

[1] Besanko D., Spulber D., (1993). "Contested Mergers and Equilibrium Antitrust Policy", Journal of Law, Economics and Organization 9 (1), $1-29$.

[2] Deneckere R., Davidson C., (1985). "Incentives to form coalitions with Betrand competition", Rand Journal of Economics 16, 473-86.

[3] Horn H., Person L., (2001). "Endogenous mergers in concentrated markets", International Journal of Industrial Organization 9, 1213-1243.

[4] Kamien M., Zang I., (1990). "The limits of monopolization through acquisition", Quarterly Journal of Economics, Vol. CV, 456-500.

[5] McAfee, P., Williams, M., (1992). "Horizontal mergers and antitrust policy", Journal of Industrial Economics XL, June 1992, 181-187.

[6] Medvedev A., (2004). "Efficiency defense and fuzziness in merger regulation", mimeo.

[7] Monti M., (2002). "The Commission notice on merger remedies - one year after", speech delivered at the Symposium on "Guidelines for merger remedies", Paris, January 2002. 
[8] Motta M., Polo M., Vasconcelos H., (2002). "Merger remedies in the European Union: and overview", paper presented at the Symposium on "Guidenlines for merger remedies", Paris, January 2002.

[9] Motta M., (2004). "Competition policy: theory and practice", Cambridge University Press, 2004.

[10] Neven D., Roller L., (2000). "Consumer surplus vs. welfare standard in a political economy model of merger control", WZB discussion paper FS IV 00-15.

[11] Perry, M., Porter, R., (1985). "Oligopoly and the incentive for horizontal merger", American Economic Review 75, March 1985, 219-27.

[12] Salant S., Switzer S., and Reynolds R., (1983). "Losses from horizontal merger: the effects of an exogenous change in industry structure on Cournot-Nash equilibrium", Quarterly Journal of Economics 98(2), 185199.

[13] Shapiro C., Farrell J., (1990). "Horizontal mergers: equilibrium analysis", American Economic Review, March 1990, 107-26.

[14] Shapiro C., Farrell J., (2001). "Scale Economies and Synergies", Antitrust Law Journal 68(3), 685-710.

[15] Williamson O., (1968). "Economics as an antitrust defence: the welfare trade-off', American Economic Review 58(1), 18-36

[16] Werden G., (1996). "A robust test for consumer welfare enhancing mergers among sellers of differentiated products", Journal of Industrial Economics 44(4), 409-413.

[17] Yao D., Dahdouh T., (1993). "Information problems in merger decision making and their impact on development of an efficiencies defense", Antitrust Law Journal 62(1), 23-45. 


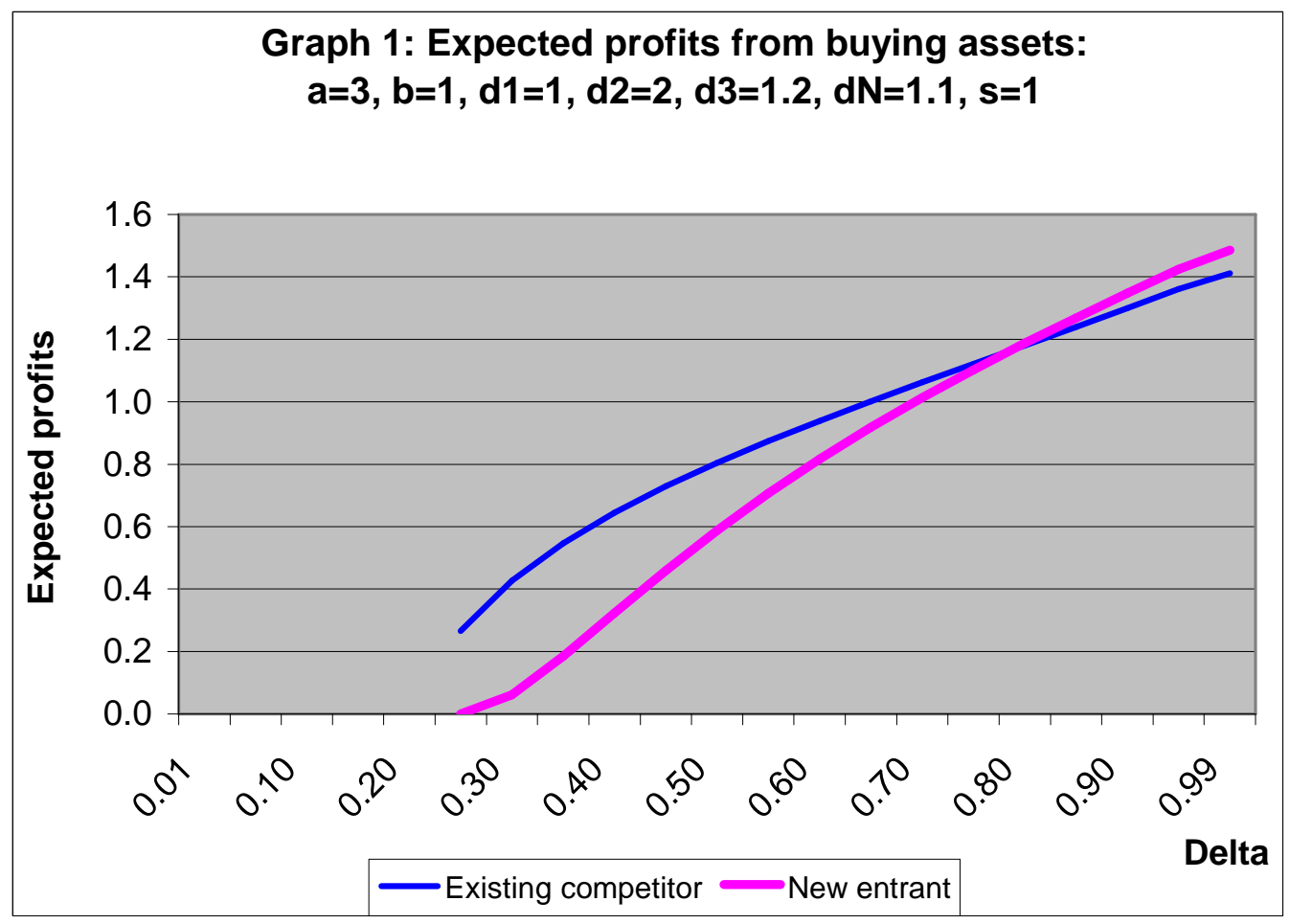

Fugure 1: Required divesture (Delta,\%) for given efficiencies (Alpha, \%) to keep price unchanged: $a=3.5, d=1, s=1$

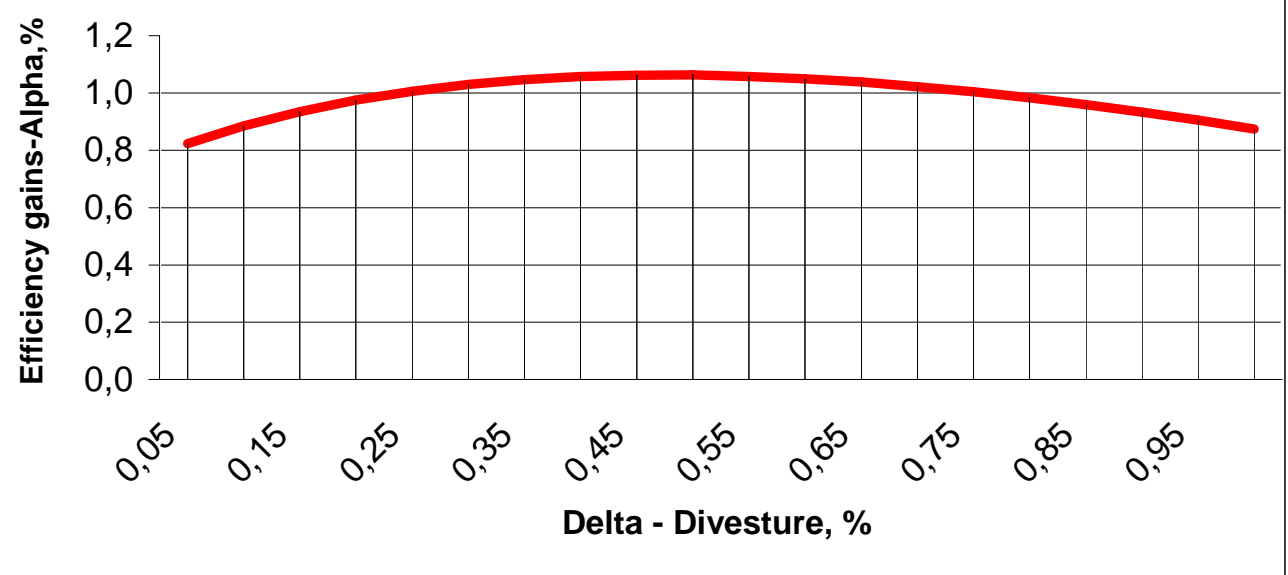


MATLAB code for the situation in which an existing competitor wins the auction but the price will increase. However, if a new entrant won the auction, the price would decrease and it would be profitable for the merging firms.

clear; tic;

$\mathrm{a}=4$;

$\mathrm{N}=100$

$\mathrm{K}=100$;

delta=linspace $(.0001,1, \mathrm{~N})$;

$\mathrm{d} 2=$ linspace $(.0001,4, \mathrm{~K})$;

$\mathrm{d} 3=$ linspace $(.0001,4, \mathrm{~K})$;

$\mathrm{dN}=$ linspace $(.0001,4, \mathrm{~K})$;

$\mathrm{X} 1=0 ; \mathrm{X} 2=0 ; \mathrm{X} 3=0 ; \mathrm{X} 4=0 ; \mathrm{X} 5=0 ; \mathrm{X} 6=0$;

$\mathrm{X} 7=0 ; \mathrm{X} 8=0 ; \mathrm{X} 9=0 ; \mathrm{X} 10=0 ; \mathrm{X} 11=0 ; \mathrm{X} 12=0$;

for $\mathrm{i} 1=1: \mathrm{N}$

for $\mathrm{i} 2=1: \mathrm{K}$

for $\mathrm{i} 3=1: \mathrm{K}$

for $\mathrm{i} 4=1: \mathrm{K}$

deltai=delta(i1);

$\mathrm{d} 2 \mathrm{i}=\mathrm{d} 2(\mathrm{i} 2)$;

$\mathrm{d} 3 \mathrm{i}=\mathrm{d} 3(\mathrm{i} 3)$;

$\mathrm{dNi}=\mathrm{dN}(\mathrm{i} 4)$;

$\mathrm{I} 1=(\mathrm{a}-1-3 * d 2 \mathrm{i}+\mathrm{d} 3 \mathrm{i})>0$

$\mathrm{I} 211=(\mathrm{a}-3+\mathrm{d} 2 \mathrm{i}+\mathrm{d} 3 \mathrm{i})>0$;

$\mathrm{I} 212=(\mathrm{a}-3 /(2-$ deltai $)+\mathrm{d} 3 \mathrm{i}+\mathrm{dNi} /$ deltai $)>0$;

$\mathrm{I} 213=(\mathrm{a}-3 /(2-$ deltai $)+\mathrm{d} 3 \mathrm{i} /(1+$ deltai $))>0$;

$\mathrm{I} 22=\left(\mathrm{a}+1-3^{*} \mathrm{~d} 2 \mathrm{i}+\mathrm{d} 3 \mathrm{i}\right)>0$;

$\mathrm{I} 231=(\mathrm{a}+1+\mathrm{d} 2 \mathrm{i}-3 * \mathrm{~d} 3 \mathrm{i})>0$;

I $232=(a-3 * d 3 i+1 /(2-$ deltai $)+d N i /$ deltai $)>0$;

$\mathrm{I} 233=(\mathrm{a}-3 * \mathrm{~d} 3 \mathrm{i} /(1+$ deltai $)+1 /(2-$ deltai $))>0$;

$\mathrm{I} 2 \mathrm{~N}=(\mathrm{a}-3 * \mathrm{dNi} /$ deltai $+1 /(2-$ deltai $)+\mathrm{d} 3 \mathrm{i})>0$;

$\%$ without divesture the price will increase

$\%$ positive output for Firm 1 before

$\%$ positive output for Firm 1 after with new entrant

$\%$ positive output for Firm 1 after with existing competitor

$\%$ positive output for Firm 2 before

$\%$ positive output for Firm 3 before

$\%$ positive output for Firm 3 after with new entrant

$\%$ positive output for Firm 3 after with existing competitor

$\%$ positive output for the new entrant with Delta assets

$\%$ Existing competitor bids higher price at an auction

$\mathrm{I} 3=\left((16 / 9)^{*}(\mathrm{a}-2 * \mathrm{~d} 3 \mathrm{i} /(1+\text { deltai })+1 /(2-\text { deltai }))^{\wedge} 2-(\mathrm{a}-3 * \mathrm{~d} 3 \mathrm{i}+1 /(2-\text { deltai })+\mathrm{dNi} / \mathrm{deltai})^{\wedge} 2-\right.$

$(\mathrm{a}-3 * \mathrm{dNi} /$ deltai+1/(2-deltai $\left.)+\mathrm{d} 3 \mathrm{i})^{\wedge} 2\right)>0$;

$\%$ it is profitable for the merging firms 1 and 2 if a new entrant buys assets

$\mathrm{I} 41=\left((\mathrm{a}-3 /(2-\text { deltai })+\mathrm{d} 3 \mathrm{i}+\mathrm{dNi} / \text { deltai })^{\wedge} 2-(\mathrm{a}-3+\mathrm{d} 2 \mathrm{i}+\mathrm{d} 3 \mathrm{i})^{\wedge} 2-(\mathrm{a}+1-3 * \mathrm{~d} 2 \mathrm{i}+\mathrm{d} 3 \mathrm{i})^{\wedge} 2\right)>0$;

$\%$ it is profitable for the merging firms 1 and 2 if an existing competitor (EC) buys assets

$\mathrm{I} 42=\left((16 / 9) *(\mathrm{a}-2 /(2-\text { deltai })+\mathrm{d} 3 \mathrm{i} /(1+\text { deltai }))^{\wedge} 2-(\mathrm{a}-3+\mathrm{d} 2 \mathrm{i}+\mathrm{d} 3 \mathrm{i})^{\wedge} 2-(\mathrm{a}+1-3 * \mathrm{~d} 2 \mathrm{i}+\mathrm{d} 3 \mathrm{i})^{\wedge} 2\right)>0$;

$\%$ price NOT increases if a new entrant $(\mathrm{N})$ buys assets

$\mathrm{I} 51=(1+\mathrm{d} 2 \mathrm{i}-1 /(2-$ deltai $)-\mathrm{dNi} / \mathrm{deltai})>0$;

$\%$ price INCREASES if an existing competitor (EC) buys assets

$\mathrm{I} 52=(\mathrm{a}-3+4 /(2-$ deltai $)-3 * \mathrm{~d} 2 \mathrm{i}-3 * \mathrm{~d} 3 \mathrm{i}+4 * \mathrm{~d} 3 \mathrm{i} /(1+$ deltai $))>0$;

$\mathrm{I}=\mathrm{I} 1 * \mathrm{I} 211 * \mathrm{I} 212 * \mathrm{I} 213 * \mathrm{I} 22 * \mathrm{I} 231 * \mathrm{I} 232 * \mathrm{I} 233 * \mathrm{I} 2 \mathrm{~N} * \mathrm{I} 3 * \mathrm{I} 41 * \mathrm{I} 42 * \mathrm{I} 51 * \mathrm{I} 52$

$\%$ if all conditions hold then it is 1 , if at least one doesn't then 0 


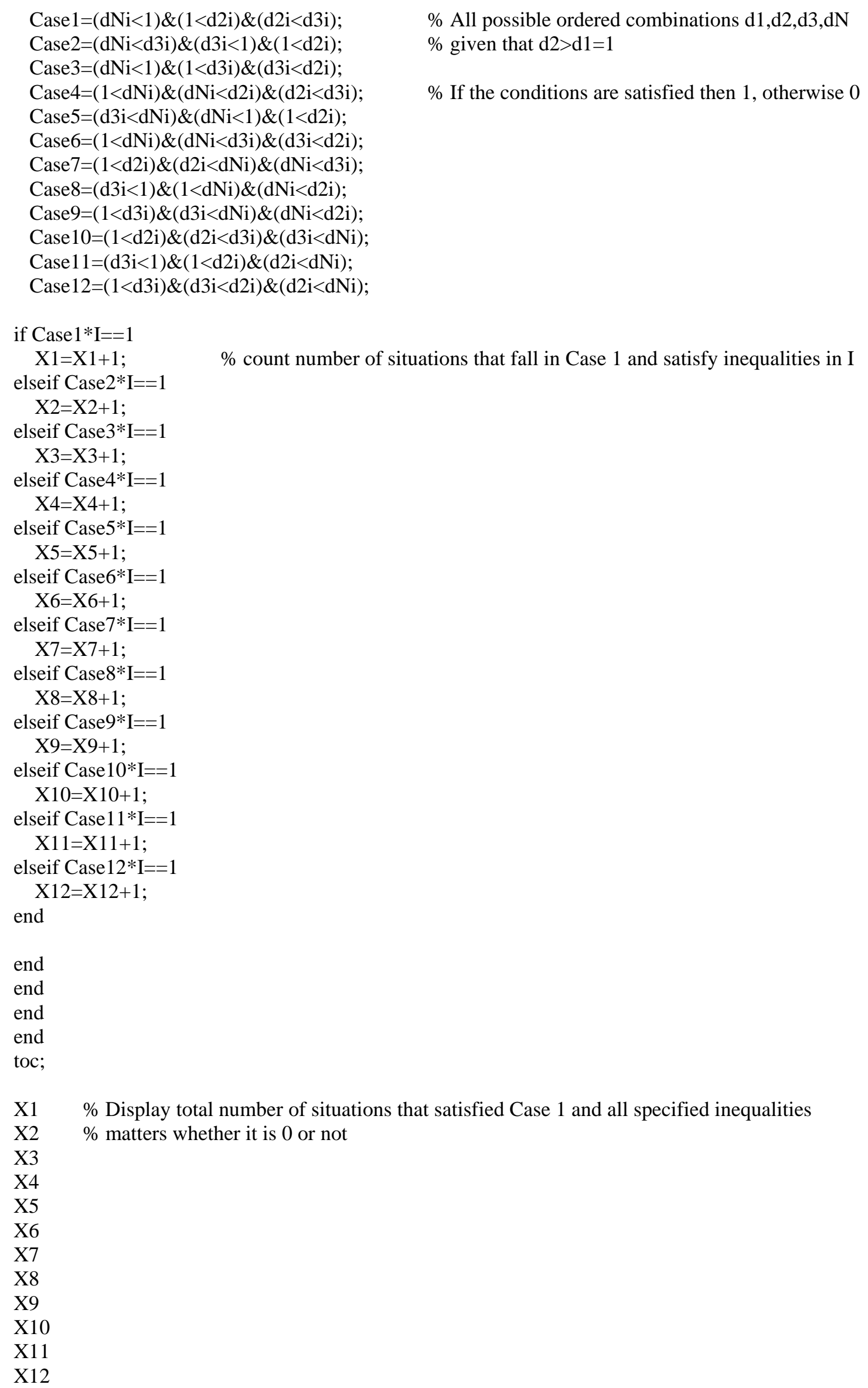

$\%$ All possible ordered combinations d1,d2,d3,dN

$\%$ given that $\mathrm{d} 2>\mathrm{d} 1=1$

$\%$ If the conditions are satisfied then 1 , otherwise 0 
CERGE-EI

P.O.BOX 882 Politických vezòù 7

11121 Prague 1

Czech Republic http://www.cerge-ei.cz 